\title{
Outcomes after thymectomy in class I myasthenia gravis
}

\author{
Tommaso Claudio Mineo, MD, and Vincenzo Ambrogi, MD, $\mathrm{PhD}$
}

Objective: The role of extended thymectomy in the treatment of class I myasthenia gravis is still controversial. This study compared the long-term outcomes of operated and nonoperated patients allocated according to their will.

\begin{abstract}
Methods: We retrospectively reviewed 47 patients with class I nonthymomatous myasthenia gravis undergoing extended thymectomy between 1980 and 2007. These patients were matched with 62 class I patients who refused surgery and received only pharmacologic therapy. Outcomes were stable remission and clinical or pharmacologic improvement. Predictors of remission were analyzed by Kaplan-Meier and Cox regression.
\end{abstract}

Results: We observed low postoperative major morbidity $(n=2 ; 4.2 \%)$ and no perioperative mortality. Heterotopic thymus was found in 22 patients $(46 \%)$. Twenty-one patients showed active germinal centers, in the heterotopic thymus in 12 patients $(57.1 \%)$. Thirty operated patients $(64 \%)$ versus 34 nonoperated patients $(55 \%)$ achieved stable remission, and 8 patients $(17 \%)$ versus 5 patients $(9 \%)$ showed pharmacologic improvement. Nine patients who had no postoperative improvement showed active ectopic thymus. Surgery was a marginal prognosticator $(P=.053)$. Early treatment ( $\leq 6$ months from symptoms onset) was the unique significant prognosticator $(P=.045)$, but this was due to the contribution of the operated patients $(P=.002)$. Other predictors of remission in the operated group were the absence of ectopic thymus $(P=.007)$ with no germinal centers $(P=.009)$. No significant predictor of remission was found in the nonoperated group.

Conclusions: Extended thymectomy achieved a more rapid remission than after nonsurgical treatment of class I myasthenia gravis. Significantly better outcomes resulted when thymectomy was performed within 6 months from the onset of symptoms. (J Thorac Cardiovasc Surg 2013;145:1319-24)

Class I myasthenia gravis (MG) is characterized by disturbances limited to the oculomotor and levator palpebrae muscles, causing diplopia and ptosis, while all other muscle strength is normal. Approximately one third of all patients with MG are diagnosed with class I. ${ }^{1}$ MG remains purely ocular in $15 \%$ of cases, ${ }^{2}$ but approximately one half of patients will progress within 2 years. ${ }^{3}$ Myasthenic thymus usually shows histologic alterations varying from lymphoid hyperplasia to atrophy or tumor. ${ }^{4}$ The production of autoantibodies by thymic B-cells is the basis of MG pathogenesis. ${ }^{5}$

The opportunity of thymectomy in class I MG is currently debated, some studies supporting ${ }^{6,7}$ and others opposing its effectiveness. ${ }^{8,9}$ The relative rarity of this clinical condition prevents the collection of large series. Thus, we retrospectively compared the outcomes of patients who underwent extended thymectomy for class I MG with those treated only with medical therapies.

\footnotetext{
From the Department of Thoracic Surgery, Multidisciplinary Myasthenia Gravis Unit, Policlinico Tor Vergata University, Rome, Italy.

Disclosures: Authors have nothing to disclose with regard to commercial support.

Received for publication Aug 15, 2012; revisions received Oct 24, 2012; accepted for publication Dec 11, 2012; available ahead of print Jan 14, 2013.

Address for reprints: Tommaso Claudio Mineo, MD, Cattedra di Chirurgia Toracica, Policlinico Tor Vergata, Viale Oxford 81, 00133 Rome, Italy (E-mail: mineo@ med.uniroma2.it).

$0022-5223 / \$ 36.00$

Copyright (c) 2013 by The American Association for Thoracic Surgery

http://dx.doi.org/10.1016/j.jtcvs.2012.12.053
}

\section{MATERIALS AND METHODS Patients}

From 1980 to 2007, a total of 136 patients diagnosed with class I MG according to the MG Foundation of America ${ }^{10}$ and with no evidence of mediastinal mass were studied in our dedicated multidisciplinary MG unit. Neurologists with extensive experience in MG formulated the diagnosis, which was based on clinical features consisting of oculomotor and levator palpebrae muscle weakness originating from binocular diplopia and asymmetric ptosis. Features also included 1 or both of the following: (1) muscle strength improvement after edrophonium chloride administration and (2) primary postsynaptic disorder tested by repetitive nerve stimulation or single-fiber electromyography. Patients diagnosed after 1994 also were tested for circulating anti-acetylcholine receptor (AChR) antibodies. Computed tomography of the chest was performed in all patients. After panel consultation, extended thymectomy was proposed to 128 patients. Patients were informed about the lack of consensus regarding surgery in class I nonthymomatous MG. After providing the patients with exhaustive information about the pros and cons and long-term results of surgery versus no surgery, the patients were asked to make a decision. Sixty-six patients chose surgical treatment. None of them received specific medical therapy (ie, anticholinesterase agent or corticosteroids) before surgery. Both operated and nonoperated patients were followed by the same medical staff in the Multidisciplinary Myasthenia Gravis Unit.

\section{Study Design}

This was a retrospective study comparing patients with class I MG who underwent thymectomy followed by medical therapy with patients treated only with medical therapy. As reported in the previous section, the 2 groups were generated by a self-allotment criteria based on the patient's preference.

The review study was authorized by the ethical committee and institutional review board of Tor Vergata University and activated in 2010. 


\section{Abbreviations and Acronyms \\ $\mathrm{AChR}=$ anti-acetylcholine receptor \\ $\mathrm{MG}=$ myasthenia gravis}

Written and fully informed consent to the use of personal data was obtained from each patient involved in the study. The incidental discovery of an unexpected thymoma implied exclusion from the study $(\mathrm{n}=19)$. Clinical information was retrieved from the MG unit database collected during hospital admissions. Patients undergoing operation before 2000 and therefore classified according to Osserman ${ }^{11}$ were retrospectively reclassified. Patients' recruitment was interrupted in 2007 to have a minimum followup of at least 5 years.

\section{Surgical Group}

A total of 47 patients underwent extended thymectomy via median sternotomy by the same surgeon (TCM). Demographic data are summarized in Table 1.

The operation was accomplished under general anesthesia with single-lung ventilation. All procedures were preceded by the insertion of an arterial line and a central venous catheter. Electrocardiogram, noninvasive blood pressure, pulse oximetry, end-tidal carbon dioxide, airway pressure, ventilatory volume, and fraction of inspired oxygen were routinely monitored. Only short-acting, nondepolarizing neuromuscular relaxants were occasionally used. The thymus was approached via a total median sternotomy defined as T-3b according to the MG Foundation of America. ${ }^{12}$ Resection routinely included the thymus gland, perithymic adipous tissue, perithymic cervical, perithyroid and retroinnominate vein regions, and fatty tissue in the aortocaval groove, the aortopulmonary window, and both pericardiophrenic sinuses. Thymectomy was considered extended according to Sonnet and Jaretzki. ${ }^{13}$ In the postoperative period, an anticholinesterase agent or corticosteroids were started when necessary.

\section{Thymic Specimen Evaluation}

Thymic and extrathymic tissues were routinely examined. Hematoxylin-eosin-stained sections were prepared from paraffin-embedded blocks and examined under low magnification $(\times 20)$. Ectopic thymus was searched by randomly sampling 1 of every 5 sections of fat tissue inclusions. Germinal centers were detected by examining visual fields of at least 5 sections of the thymus stained with monoclonal antibodies against CD23 ${ }^{14}$ Cytoplasmic staining with anti-human CD23 was scored as positive by an experienced pathologist.

\section{Follow-up}

Patients were visited for follow-up in the dedicated MG unit by the same team of physicians at 3 months after the first year and then every 6 months. Other information was obtained by telephone. Medication (ie, anticholinesterase or steroids) and dosage in the 2 groups were timely recorded. The dose of medications was progressively reduced and eventually withdrawn if the patient became symptom-free. No immunosuppressive drug was used.

The therapeutic effect and symptomatic response to the different therapies was established for each patient according to the MG Foundation of America postinterventus status classification. ${ }^{10}$ Stable remission was defined as no symptoms or signs of ocular MG at careful examination for at least 12 months achieved without therapy, except for low-dose steroids ( $\leq 10 \mathrm{mg} / \mathrm{d}$ methylprednisolone). This caveat was adopted to define complete remission, given that in a few instances the neurologists administered occasional low-dose corticosteroids despite the disappearance of symptoms for more than 1 year. $^{7,15}$
Improvement was defined as amelioration of ocular symptoms (clinical) or a long-lasting decrease in MG therapy (pharmacologic). Patients whose ocular symptoms or administered medication dosages were stable were scored as "unchanged." Likewise, those patients who developed more serious ocular symptoms or required an increase in medical therapy, or whose symptoms progressed toward the other classes, were all defined as having "worsened disease."

\section{Statistical Analysis}

Values of descriptive variables were presented as median (interquartile range). All analyses were performed with the Statistical Package for the Social Sciences (SPSS Inc, Chicago, Ill). Because of the relatively small sample size compared with the multiplicity and the non-normal distribution of the investigated variables, the nonparametric tests were prudentially used. In a preliminary step, the homogeneity of the 2 groups was tested for demographic features and main diseaserelated variables. The interdependence between the principal clinical variables and the outcomes was evaluated in each group by univariate analysis.

Thereafter, the effect of each variable on stable remission was determined by the Kaplan-Meier estimates of time to stable remission at specific time points. Time to stable remission was defined as the time between the day of surgery or the beginning of medical treatment, and the date of stable remission. Patients who had not achieved stable remission were censored. Multivariate analysis of the entire population to select the most significant predictor of remission was conducted by Cox regression analysis.

\section{RESULTS}

The 2 groups were homogeneous for all demographic and clinical variables investigated as shown in Table 1 . There was no perioperative mortality in the operated group, whereas major morbidity was experienced in 2 patients $(4.2 \%)$ : 1 case of sternal infection and 1 case of pneumonia and pleural effusion. No myasthenic crisis occurred after surgery.

Histologic examination showed hyperplasia in 27 patients $(58 \%)$ and normal thymus in 20 patients $(42 \%)$. In these specimens, germinal centers were detected in 21 of the native thymuses $(45 \%): 12(12 / 27,44 \%)$ hyperplastic and $9(9 / 20,45 \%)$ normal. Heterotopic thymic tissue was found in 22 patients $(47 \%)$ and was more frequent in the normal atrophic $(12 / 20,60 \%)$ than in the hyperplastic $(10 / 27,37 \%)$ native thymus. This tissue was located in the cervical region $(\mathrm{n}=10,45 \%)$, aortopulmonary window $(\mathrm{n}=5,22 \%)$, anterior mediastinum $(\mathrm{n}=18,81 \%)$, and right $(\mathrm{n}=1,5 \%)$ and left $(\mathrm{n}=2,9 \%)$ pericardiophrenic angles; 14 patients had ectopic thymic tissue at 2 different sites. Presence of germinal centers was proved in more than one half $(12 / 22,54 \%)$ of the patients with ectopic thymus.

\section{Long-Term Results}

Complete follow-up was available in all patients (Table 1). Two patients died at 45 and 96 months from the operation. In both cases, death was related to cardiovascular disease. Four patients died in the nonoperated group, 2 of them as the result of complications related to MG worsening.

The analysis of prescribed medications initially documented a lower median dosage for both anticholinesterase 
TABLE 1. Clinical features of the two groups (operated vs nonoperated)

\begin{tabular}{|c|c|c|c|}
\hline Clinical features & Operated $(n=47)$ & Nonoperated $(n=62)$ & $P$ valu \\
\hline Age, median y (IQR) & $19(16-24)$ & $19(16-25)$ & .380 \\
\hline Early onset $\leq 16$ y vs $>16$ y & 14 vs 33 & 16 vs 46 & 646 \\
\hline Sex, male vs female & 17 vs 30 & 21 vs 41 & .804 \\
\hline Symptom-therapy interval, median mo (IQR) & $6(4-21)$ & $6(4-23)$ & .860 \\
\hline Early treatment $\leq 6$ mo vs $>6$ mo & 22 vs 25 & 24 vs 38 & .397 \\
\hline $\mathrm{AChR}$ antibody dosage at diagnosis, median $\mathrm{nmol} / \mathrm{L}$ (IQR)* & $17(13-21)$ & $19(15-26)$ & 690 \\
\hline Follow-up, median mo (IQR) & $100(70-178)$ & $116(80-160)$ & .973 \\
\hline 1-y global improvement, no. of patients ( $\%)$ & $10(21 \%)$ & $5(8 \%)$ & .048 \\
\hline 1-y MGFA class progression, no. of patients ( $\%$ ) & $6(13 \%)$ & $13(26 \%)$ & .266 \\
\hline 5-y global improvement, no. of patients (\%) & $27(58 \%)$ & $21(34 \%)$ & .035 \\
\hline 5-y MGFA class progression, no. of patients ( $\%)$ & $9(19 \%)$ & $16(26 \%)$ & .413 \\
\hline Total stable remission rate, no. of patients (\%) & $30(64 \%)$ & $34(55 \%)$ & .347 \\
\hline Time to remission, median mo (IQR) & $17(5-29)$ & $36(29-48)$ & .032 \\
\hline
\end{tabular}

$I Q R$, Interquartile range; $A C h R$, anti-acetylcholine receptor; $M G F A$, Myasthenia Gravis Foundation of America. *Eight-six patients available.

and steroid drugs in the operated group. This difference attenuated after 5 years of follow-up (Figure 1).

In the operated group, 30 patients $(64 \%)$ achieved stable remission and 8 patients $(17 \%)$ showed clinical or pharmacologic improvement. The remaining 9 patients (19\%) experienced worsening of the symptoms with class progression. Of note, all these cases presented active ectopic thymic islets in the resected mediastinal fat and higher median titer of AChR antibodies than the other operated patients. The median (interquartile range) value of $\mathrm{AChR}$ antibodies was as follows: 24 (11-34) $\mathrm{nmol} / \mathrm{L}$ versus 4 (0-9) $\mathrm{nmol} / \mathrm{L}$ $(P=.02)$ at 6 months, $25(8-36) \mathrm{nmol} / \mathrm{L}$ versus $5(0-10)$ $\mathrm{nmol} / \mathrm{L}(P=.03)$ at 12 months, and $27(10-38) \mathrm{nmol} / \mathrm{L}$ versus $3(0-5) \mathrm{nmol} / \mathrm{L}(P=.02)$ at 24 months, respectively. In the nonoperated group, 34 patients $(55 \%)$ achieved stable remission and clinical symptoms improved or prescription dosages were reduced in 5 patients. Progression to generalized MG was observed in 16 patients ( $26 \%$ ), whereas 3 patients $(48 \%)$ remained only with ocular symptoms. None of these patients underwent thymectomy during the study period.

Likewise, the proportion of patients who improved was significantly higher in the operated group: $21 \%$ versus $8 \%$ at 1 year $(P=.048)$ and $58 \%$ versus $34 \%$ at 5 years $(P=.035)$ (Table 1). The impact of main prognostic factors on improvement in operated and nonoperated patients is summarized in Table 2.

In the whole study population, Kaplan-Meier analysis showed a more rapid positive outcome of operated versus nonoperated patients with earlier median time to stable remission (17 vs 36 months) and greater estimated rate of remission at 5 years $(53 \%$ vs $32 \%)$. Only early treatment $(\leq 6$ months) was a significant predictor $(P=.045)$ of stable remission, whereas surgery was a marginal prognostic factor $(P=.053)$ (Figure 2$)$. However, the positive impact of early treatment was only due to the weight of "early operated" patients $(P=.002)$ and not to "early treated" nonoperated patients $(P=.51)$. Indeed, early surgery allowed remission in $77 \%$ of the cases.
In the operated group, the presence of ectopic thymus $(P=.007)$, especially with concomitant germinal centers $(P=.009)$, was found to be a significant negative predictor
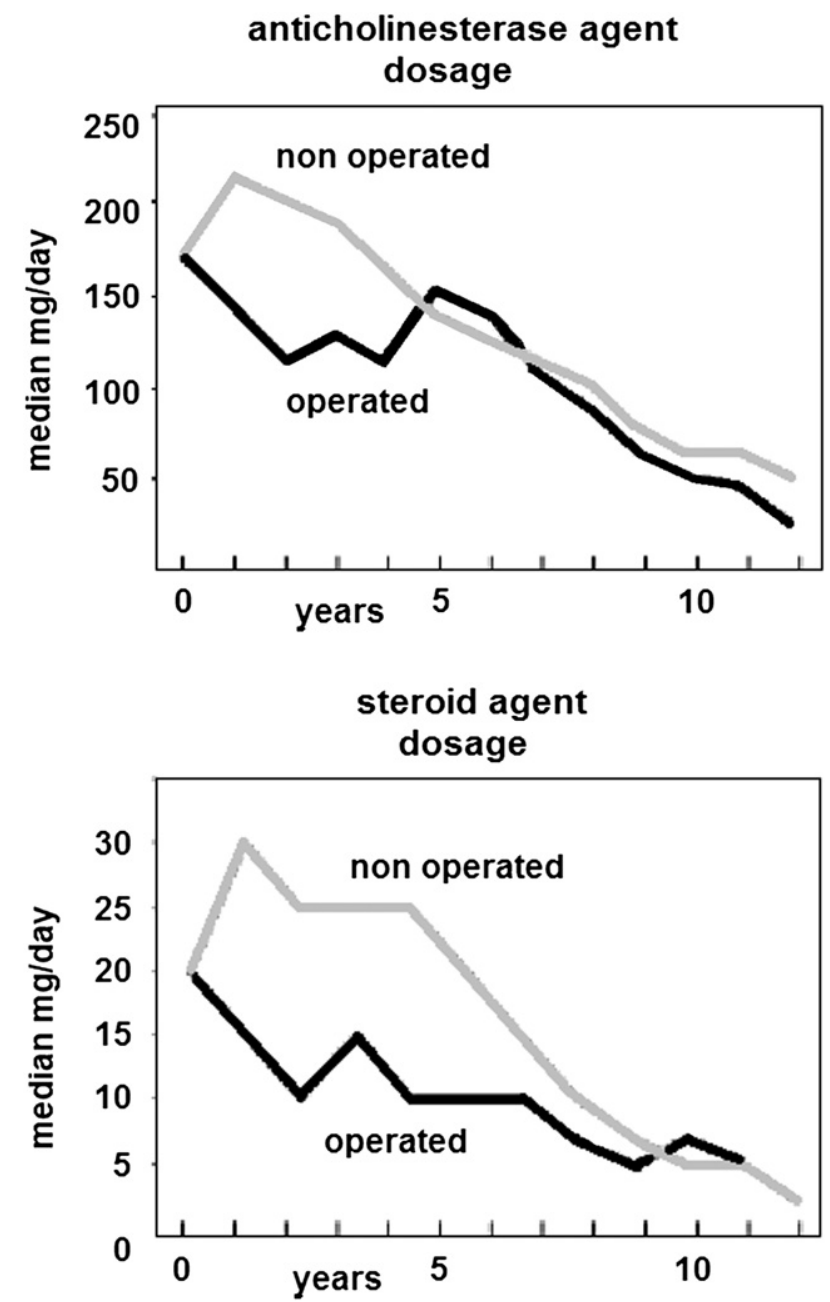

FIGURE 1. Median dosage changes in both study groups for anticholinesterase (top) and steroid (bottom) drugs. 
TABLE 2. Interdependence between risk factors and clinical improvement in each study group

\begin{tabular}{|c|c|c|c|c|c|c|}
\hline & \multicolumn{2}{|c|}{$\begin{array}{c}\text { Operated } \\
\text { Postoperative status }\end{array}$} & \multirow[b]{2}{*}{$P$ value } & \multicolumn{2}{|c|}{$\begin{array}{c}\text { Nonoperated } \\
\text { Posttreatment status }\end{array}$} & \multirow[b]{2}{*}{$P$ valu } \\
\hline & Improved & Unchanged or worsened & & Improved & Unchanged or worsened & \\
\hline \multicolumn{7}{|l|}{ Sex } \\
\hline Male & 13 & 4 & .52 & 12 & 9 & .58 \\
\hline Female & 25 & 5 & & 27 & 14 & \\
\hline \multicolumn{7}{|l|}{ Early onset } \\
\hline$\leq 16 \mathrm{y}$ & 12 & 2 & .58 & 13 & 3 & .08 \\
\hline$>16 \mathrm{y}$ & 26 & 7 & & 26 & 20 & \\
\hline \multicolumn{7}{|l|}{ Early treatment } \\
\hline$\leq 6 \mathrm{mo}$ & 19 & 3 & .36 & 16 & 7 & .43 \\
\hline$>6 \mathrm{mo}$ & 19 & 6 & & 23 & 16 & \\
\hline \multicolumn{7}{|l|}{ Histology } \\
\hline Hyperplasia & 22 & 5 & .89 & NA & NA & \\
\hline Normal & 16 & 4 & & NA & NA & \\
\hline \multicolumn{7}{|c|}{ Germinal centers } \\
\hline No & 24 & 2 & .02 & NA & NA & \\
\hline Yes & 14 & 7 & & NA & NA & \\
\hline \multicolumn{7}{|c|}{ Ectopic thymic tissue } \\
\hline No & 25 & - & .0001 & NA & NA & \\
\hline Yes & 13 & 9 & & NA & NA & \\
\hline \multicolumn{7}{|c|}{ Ectopic active tissue } \\
\hline No & 16 & - & .0001 & NA & NA & \\
\hline Yes & - & 9 & & NA & NA & \\
\hline
\end{tabular}

NA, Not applicable.

of remission. No significant factor predicting stable remission was found in the nonoperated group.

Cox regression analysis showed that early treatment $(\leq 6$ months) was the most significant predictor of remission $(P=.026)$. Noteworthy surgical therapy was a positive prognostic factor if survival analysis was restricted to 5 years follow-up $(P=.041)$ (Table 3$)$. The reasonable

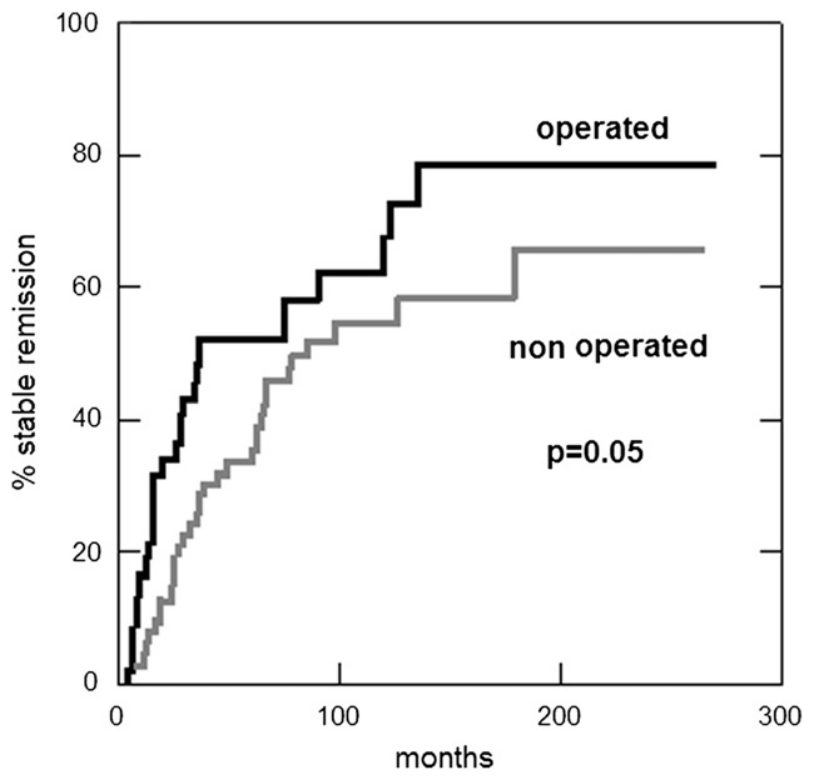

FIGURE 2. Kaplan-Meier remission curve for operated and nonoperated patients. explanation is that those patients who benefit from massive thymic tissue removal improve within the first 5 years. Conversely, the probability of remission becomes less likely after 5 years. The late censorship of these subjects might have affected statistical results shading the positive effect of thymectomy.

\section{DISCUSSION}

Although thymectomy is considered an integrated action in the treatment of AChR antibody-positive MG, in subjects with ocular symptoms only, surgery is difficult to accept. ${ }^{16,17}$ Thymectomy is usually performed to control or stop symptoms, to avoid the possible progression of the disease, and to reduce the intake of pharmacologic therapy, minimizing unpleasant side effects. However, the mildness of symptoms in class I MG often leads both neurologists and patients to avoid surgery. ${ }^{8,9}$ In addition, the relative rarity of the disease is still an obstacle in the collection of a larger series and the setup of prospective randomized studies.

Nevertheless, there is a strong rationale for thymectomy even in class I MG. In this class, there is a consistent production of AChR antibodies in more than $50 \%$ of the patients. ${ }^{3}$ Antibody production often takes place in the noninvoluted thymic gland. ${ }^{18,19}$ Many studies suggest that the synthesis of AChR antibodies is likely situated in the activated thymic regions (eg, B-cell follicles and germinal centers), where B-lymphocytes differentiate into cells producing antibodies with high affinity toward antigens. ${ }^{20-22}$ 
TABLE 3. Cox regression analysis

\begin{tabular}{|c|c|c|c|c|c|c|c|c|}
\hline \multirow[b]{2}{*}{ Selection } & \multirow[b]{2}{*}{ Variables } & \multirow[b]{2}{*}{ B } & \multirow[b]{2}{*}{ SE } & \multirow[b]{2}{*}{ Wald } & \multirow[b]{2}{*}{$P$ value } & \multirow[b]{2}{*}{$\operatorname{Exp}(\mathbf{B})$} & \multicolumn{2}{|c|}{$\mathbf{9 5} \% \mathrm{CI}$} \\
\hline & & & & & & & Lower & Upper \\
\hline \multirow[t]{2}{*}{ Unlimited follow-up } & Operated vs nonoperated & 0.407 & 0.252 & 2.612 & .106 & 1.502 & 0.917 & 2.459 \\
\hline & Symptom-treatment interval ( $\leq 6 \mathrm{mo}$ vs $>6 \mathrm{mo}$ ) & 0.561 & 0.252 & 4.979 & .026 & 1.753 & 1.071 & 2.870 \\
\hline \multirow[t]{2}{*}{ 5-y follow-up } & Operated vs nonoperated & 0.621 & 0.328 & 3.579 & .041 & 1.861 & 0.978 & 3.540 \\
\hline & Symptom-treatment interval ( $\leq 6 \mathrm{mo}$ vs $>6 \mathrm{mo}$ ) & 0.370 & 0.319 & 1.347 & .246 & 1.448 & 0.775 & 2.703 \\
\hline
\end{tabular}

SE, Standard error; $C I$, confidence interval.

Removal of as much thymic parenchyma as possible and the active tissue should be an effective treatment.

Our investigations demonstrated several relevant points. First, extended thymectomy proved safe and effective to achieve stable remission. We observed no mortality and a low rate of major morbidities. Surgery had a more rapid effect than pharmacologic therapy, and this was supported by the shorter median time to remission. When the analysis was restricted to the first 5 years from treatment, more than one half of our operated patients achieved stable remission, and this rate is similar to the most encouraging series in the literature. ${ }^{23-25}$

Second, the clinical-pharmacologic improvement was comparatively delayed in the nonoperated group, and these patients experienced a greater probability of progression toward more severe classes of MG. This finding could be evidence that pharmacologic therapy is less effective in counteracting the natural history of the disease.

Third, in partial contrast with other studies ${ }^{26}$ in the current study, surgical procedure did not completely protect from MG progression. Indeed, $20 \%$ of the thymectomized patients had disease progression within 1 year from surgery. This event is strictly correlated to the presence of active ectopic tissue and is characterized by a increment of AChR antibody titer. Zuckerman and colleagues ${ }^{27}$ have recently reported that heterotopic active thymic islets can be present in adjacent mediastinal areas. Ponseti and colleagues ${ }^{28}$ suggested that their persistence may impair the symptomatic improvement after thymectomy in any class. In a previous article about class III MG, we discussed the prognostic importance of ectopic thymic tissue, which may frequently host germinal centers. ${ }^{14}$ The production of AChR antibodies could take place specifically in these areas as a result of a dysregulated autoimmune response to epithelioid cells. This suggests the critical role of germinal centers in the pathogenesis of MG. ${ }^{20,21}$ The presence of this actively antibodyproducing thymic tissue may coexist with a normal thymus and correlates to worse outcome after thymectomy. These patients should receive more aggressive clinical strategy with closer follow-up, preventive use of immunosuppressive drugs, and eventually reoperation. The elevated failure rate after surgery demonstrates the difficulty of achieving a total clearance from ectopic foci despite an extensive operation. A question arises from this finding about opportunity of a transsternal approach in a poor symptomatic disease. It suggests that a minimally invasive thymectomy seems to be more appropriate in patients with class I MG.

Finally, both univariate and multivariate analyses indicate that extended thymectomy has the best results when performed within the first 6 months from the onset of ocular symptoms. More than three quarters of the patients undergoing operation within 6 months achieved remission. Only one half of those with a longer interval experienced the same positive outcome. We hypothesize that early treatment prevents the establishment of active heterotopic germinal centers.

\section{Study Limitations}

The retrospective nature of the study represents the major obvious limitation. The arbitrary criteria of allocation of the 2 groups based on patients' auto-determination is another limitation. However, this method is reasonable for a disease lacking universally accepted therapeutic guidelines. This method was approved and authorized by our internal ethical committee. Despite the empiric allotment criteria, the 2 groups were statistically homogeneous in all clinical features investigated. Another limit, due to the relative rarity of the condition, is the wide timespan required to gather a consistent sample size. Nevertheless, our study provides valuable data based on an experienced single surgeon who always performed an intentional extended thymectomy. Last, the exemption of occasional low-dose steroids for complete remission may have a benefit on time to remission and evoke some criticism about data interpretation. However, this caveat was already used in the literature $e^{7,15}$ and was adopted for the evaluation of both groups; therefore, it does not produce a bias when comparing the outcomes of the 2 treatments.

\section{CONCLUSIONS}

Early diagnosis ( $\leq 6$ months) in nonthymomatous class I MG is the most significant predictor of stable remission. Extended thymectomy achieved a more rapid remission than nonsurgical treatment of class I MG. Significantly better outcomes resulted when the operation was performed within 6 months from the diagnosis with an impact on the natural history of the disease. We still agree with the 20 -year-old statement by Buckingham and colleagues ${ }^{29}$ : "It seems likely that future discoveries will permit the management of MG without surgical intervention, but, for the 
present, the biological role of thymectomy for these unfortunate patients has been widely demonstrated." Future studies may validate new therapeutic measures, but at present thymectomy remains the best way to approach class I nonthymomatous MG.

The authors thank Alfonso Baldi, MD, for the effort in managing the immunohistochemical workup, and Leonardo Palombi, MD, for help in editing the statistical section of the study. The authors also thank all the staff members of the Myasthenia Gravis Unit of the Tor Vergata University, including neurologists, anesthesiologists, intensivists, psychologists, physiotherapists, and nurses, for professionalism and efforts covering a period more than 25 years.

\section{References}

1. Mantegazza R, Baggi F, Antozzi C, Confalonieri P, Morandi L, Bernasconi P, et al. Myasthenia gravis (MG): epidemiological data and prognostic factors. Ann N Y Acad Sci. 2003;998:413-23.

2. Sathasivam S. Steroids and immunosuppressant drugs in myasthenia gravis. Neurology. 2008;4:317-27.

3. Grob D, Brunner N, Namba T, Pagala M. Lifetime course of myasthenia gravis. Muscle Nerve. 2008;37:141-9.

4. Raica M, Cimpean AM, Ribatti D. Myasthenia gravis and the thymus gland. A historical review. Clin Exp Med. 2008;8:61-4.

5. Sommer N, Willcox N, Harcourt GC, Newsom-Davis J. Myasthenic thymus and thymoma are selectively enriched in acetylcholine receptor-reactive T cells. Ann Neurol. 1990;28:312-9.

6. Nakamura H, Taniguchi Y, Suzuki Y, Tanaka Y, Ishiguro K, Fukuda M, et al. Delayed remission after thymectomy for myasthenia gravis of the purely ocular type. J Thorac Cardiovasc Surg. 1996;112:371-5.

7. Liu Z, Feng H, Yeung SC, Zheng Z, Liu W, Ma J, et al. Extended transsternal thymectomy for the treatment of ocular myasthenia gravis. Ann Thorac Surg. 2011;92:1993-9.

8. Gilbert ME, De Sousa EA, Savino PJ. Ocular myasthenia gravis treatment: the case against prednisone therapy and thymectomy. Arch Neurol. 2007;6:1790-2.

9. Chavis PS, Stickler DE, Walker A. Immunosuppressive or surgical treatment for ocular myasthenia gravis. Arch Neurol. 2007;64:1792-4.

10. Jaretzki A III, Barohn RJ, Ernstoff RM, Kaminski HJ, Keesey JC, Penn AS, et al. Myasthenia gravis: recommendations for clinical research standards. Task Force of the Medical Scientific Advisory Board of the Myasthenia Gravis Foundation of America. Ann Thorac Surg. 2000;70:327-34.

11. Osserman KE. Clinical aspects. In: Osserman KE, ed. Myasthenia Gravis. New York, NY: Grune \& Stratton; 1958:80-1.

12. Jaretzki A III, Barohn RJ, Ernstoff RM, Kaminski HJ, Keesey JC, Penn AS, Sanders DB. Myasthenia gravis: recommendations for clinical research standards. Task Force of the Medical Scientific Advisory Board of the Myasthenia Gravis Foundation of America. Neurology. 2000;55:16-23.

13. Sonnet JR, Jaretzki A III. Thymectomy for nonthymomatous myasthenia gravis. A critical review. Ann NY Acad Sci. 2008;1132:315-28.

14. Ambrogi V, Mineo TC. Active ectopic thymus predicts poor outcome after thymectomy in class III myasthenia gravis. J Thorac Cardiovasc Surg. 2012;143: 601-6.

15. Miano MA, Bosley TM, Heiman-Patterson TD, Reed J, Sergott RC, Savino PJ, et al. Factors influencing outcome of prednisone dose reduction in myasthenia gravis. Neurology. 1991;41:919-21.

16. Evoli A, Batocchi AP, Provenzano C, Ricci E, Tonali P. Thymectomy in the treatment of myasthenia gravis: report of 247 patients. J Neurol. 1988;235:272-6.

17. Hatton PD, Diehl JT, Daly BD, Rheinlander HF, Johnson H, Schrader JB, et al. Transsternal radical thymectomy for myasthenia gravis: a 15 -year review. Ann Thorac Surg. 1989;47:838-40.

18. Masaoka A, Yamakawa Y, Niwa H, Fukai I, Kondo S, Kobayashi M, et al. Extended thymectomy for myasthenia gravis patients-a 20-year review. Ann Thorac Surg. 1996;62:853-9.
19. Okumura M, Ohta M, Takeuchi Y, Shiono H, Inoue M, Fukuhara K, et al. The immunologic role of thymectomy in the treatment of myasthenia gravis: implication of thymus-associated B-lymphocyte subset in reduction of the antiacetylcholine receptor antibody titer. J Thorac Cardiovasc Surg. 2003;126: 1922-8.

20. Roxanis I, Micklem K, McConville J, Newsom-Davis J, Willcox N. Thymic myoid cells and germinal center formation in myasthenia gravis; possible roles in pathogenesis. J Neuroimmunol. 2002;125:185-97.

21. Mori T, Nomori H, Ikeda K, Kobayashi H, Iwatani K, Kobayashi T. The distribution of parenchyma, follicles, and lymphocyte subsets in thymus of patients with myasthenia gravis, with special reference to remission after thymectomy. J Thorac Cardiovasc Surg. 2007;133:364-8.

22. Okumura M, Inoue M, Kadota Y, Hayashi A, Tokunaga T, Kusu T, et al. Biological implications of thymectomy for myasthenia gravis. Surg Today. 2010;40: 102-7.

23. Roberts PF, Venuta F, Rendina E, De Giacomo T, Coloni GF, Follette DM, et al. Thymectomy in the treatment of ocular myasthenia gravis. J Thorac Cardiovasc Surg. 2001;122:562-8.

24. Huang CS, Hsu HS, Huang BS, Lee HC, Kao KP, Hsu WH, et al. Factors influencing the outcome of transsternal thymectomy for myasthenia gravis. Acta Neurol Scand. 2005;112:108-14.

25. Shrager JB, Nathan D, Brinster CJ, Yousuf O, Spence A, Chen Z, et al. Outcomes after 151 extended transcervical thymectomies for myasthenia gravis. Ann Thorac Surg. 2006;82:1863-9.

26. Takanami I, Abiko T, Koizumi S. Therapeutic outcomes in thymectomized patients with myasthenia gravis. Ann Thorac Cardiovasc Surg. 2009;15: 373-7.

27. Zuckerman NS, Howard WA, Bismuth J, Gibson K, Edelman H, BerrihAknin S, et al. Ectopic germinal centers in the thymus of myasthenia gravis patients show characteristics of normal germinal centers. Eur J Immunol. 2010;40:1150-61.

28. Ponseti JM, Gamez J, Vilallonga R, Ruiz C, Azem J, López-Cano M, et al. Influence of ectopic thymic tissue on clinical outcome following extended thymectomy in generalized seropositive nonthymomatous myasthenia gravis. Eur $J$ Cardiothorac Surg. 2008;34:1062-7.

29. Buckingham JM, Howard FM, Bernatz PE. The value of thymectomy in MG: a computer-assisted matched study. Ann Surg. 1976;184:453-8.

\section{APPENDIX}

Myasthenia Gravis Unit

T. C. Mineo (coordinator)

Thoracic surgery V. Ambrogi, E. Pompeo, F. Sellitri, F. Tacconi

Pathology A. Baldi

Genetics G. Novelli

Anesthesiology and intensive care M. Dauri, E. Fabbi,

F. Coniglione, A. Siglioccolo

Hematology A. Franchi, F. Buccisano

Imaging M. Stefanini

Molecular biology G. Melino

Nuclear medicine O. Schillaci

Neurology G. Bernardi, R. Massa, M. Pierantozzi

Nutritional sciences M. R. Lupattelli, A. De Lorenzo

Immunology G. Adorno

Psychology E. Fortuna

Pneumology M. Cazzola, P. Rogliani

Physical therapy A. M. Servadio, S. Lezzerini

Microbiology E. Garaci

Epidemiology and statistics L. Palombi, E. Buonomo

Infective diseases M. Andreoni, L. Sarmati, P. Sordillo 